\title{
POTENCIAL CONTRIBUIÇÃO DA AGRICULTURA FAMILIAR PARA UMA ALIMENTAÇÃO ESCOLAR SAUDÁVEL NO ESTADO DE SANTA CATARINA NO PERÍODO DE 2015 A 2017
}

\section{POTENTIAL FAMILY AGRICULTURE CONTRIBUTION TO HEALTHY SCHOOL FEEDING IN THE STATE OF SANTA CATARINA FROM 2015 TO 2017}

\author{
Gisele Assumpção Vieira \\ Universidade Comunitária da Região de Chapecó - Unochapecó \\ Chapecó, SC, Brasil \\ giselevieira@unochapeco.edu.br \\ Carla Rosane Paz Arruda Teo \\ Universidade Comunitária da Região de Chapecó - Unochapecó \\ Chapecó, SC, Brasil \\ carlateo@unochapeco.edu.br \\ Roberta Lamonatto Taglietti \\ Universidade Comunitária da Região de Chapecó - Unochapecó \\ Chapecó, SC, Brasil \\ rotagli@unochapeco.edu.br
}

\begin{abstract}
Resumo
O objetivo do estudo foi analisar a contribuição dos alimentos da agricultura familiar presentes nos editais de chamada pública dos municípios catarinenses para a alimentação escolar quanto à oferta de marcadores alimentares saudáveis, no período de 2015 a 2017, como parte de um estudo longitudinal sobre o tema. Foi realizada uma pesquisa documental de abordagem quantitativa e caráter analítico. Com base nos marcadores de alimentação saudável presentes nas chamadas públicas analisadas, foi identificado, que a quantidade média per capita de frutas e hortaliças contempla a recomendação estipulada pelo Fundo Nacional de Desenvolvimento da Educação - FNDE (200g/aluno/semana) sendo atendida tanto pela oferta de frutas $(\mathrm{r}=0,912 ; \mathrm{p}<0,01)$ como pela oferta de hortaliças $(\mathrm{r}=859 ; \mathrm{p}<0,01)$, porém a quantidade média per capita de feijões foi ínfima. Foram observadas 48 variedades no grupo das hortaliças, 35 variedades no grupo das frutas e nove variedades no grupo dos feijões, porém, a variedade do grupo das frutas e feijões se apresentou baixa se comparada à do grupo das hortaliças. Os achados permitem concluir, a partir dos alimentos presentes nas chamadas públicas, que a agricultura familiar tem relevante potencial para a oferta de uma alimentação escolar saudável no estado catarinense. Contudo, para que esse potencial se realize, é importante que os editais sejam mais bem elaborados, de forma a considerar a produção e o desenvolvimento da agricultura familiar local, com foco em alimentos saudáveis.
\end{abstract}

Palavras-chave: Segurança alimentar e nutricional. Programas e políticas de nutrição e alimentação. Desenvolvimento local. Alimentação saudável. Alimentação escolar. 
Potencial contribuição da agricultura familiar para uma alimentação escolar saudável no estado de Santa Catarina no período de 2015 a 2017
Gisele Assumpção Vieira

Carla Rosane Paz Arruda Teo

Roberta Lamonatto Taglietti

\section{Abstract}

The aim of the study was to analyze the contribution of family farming food present in public calls in the municipalities of Santa Catarina state for school feeding regarding the supply of healthy food markers, from 2015 to 2017, as part of a longitudinal study on the theme. A documentary research was conducted presenting a quantitative and analytical approach. Based on the healthy eating markers present in the analyzed public calls, the average per capita amount of fruits and vegetables meets the recommendation stipulated by the Fundo Nacional de Desenvolvimento da Educação -FNDE (200 g/student/week) being met by both the fruit supply $(\mathrm{r}=0.912 ; \mathrm{p}<0.01)$ and vegetable offer $(\mathrm{r}=859 ; \mathrm{p}$ $<0.01$ ), although the average per capita amount of beans was very extremely low. A total of 48 varieties in the vegetable group, 35 varieties in the fruit group and nine varieties in the bean group were observed. Yet, the fruit and bean group varieties were low compared to the vegetable group. The findings reported herein from the food items present in the investigated public calls allow us to conclude that family farming displays a significant potential in offering healthy school meals in the state of Santa Catarina. However, in order for this potential to be realized, it is important that public calls be better designed, in order to consider the production and development of local family farming, focusing on healthy foods.

Keywords: Food and nutrition security. Nutrition and food programs and policies. Local development. Healthy diet. School feeding

\section{Introdução}

Alimentação escolar é todo alimento oferecido no ambiente escolar, durante o período letivo, constituindo-se um direito dos alunos da educação básica pública e um dever do Estado. Desse modo, o Programa Nacional de Alimentação Escolar (PNAE) tem como objetivo promover a segurança alimentar e nutricional (SAN) dos alunos, contribuindo para o crescimento e desenvolvimento biopsicossocial e para a formação de práticas alimentares saudáveis, por meio da oferta de refeições que atendam às necessidades nutricionais durante o período em que o estudante permanece na escola (BRASIL, 2009; BRASIL, 2013).

Nessa perspectiva, o PNAE se apresenta como uma ferramenta de garantia ao direito humano à alimentação adequada, influenciando a construção de hábitos alimentares e de identidades de crianças e adolescentes (SILVA; SANTOS; SOARES, 2018). Entretanto, estudos recentes têm demonstrado que esse grupo etário está suscetível ao consumo de alimentos pouco saudáveis, conforme aponta a Pesquisa Nacional de Saúde do Escolar (PeNSE) realizada no ano de 2015 com escolares do $9^{\circ}$ ano no Brasil. Esse estudo aponta que, no universo dos adolescentes pesquisados, 13,7\% consomem 
regularmente salgados fritos, $41,6 \%$ consomem guloseimas, 26,7\% consomem refrigerantes e 31,3\% alimentos ultraprocessados (IBGE, 2016).

Concomitantemente, tem-se observado, tanto nos países em desenvolvimento quanto nos desenvolvidos, a substituição do consumo de alimentos in natura e/ou minimamente processados pelo de alimentos ultraprocessados, com evidências de que esta mudança pode ocasionar doenças crônicas não transmissíveis relacionadas à dieta (MONTEIRO et al., 2017).

O Guia Alimentar da População Brasileira recomenda que a base para uma alimentação equilibrada deva ser composta predominantemente por alimentos de origem vegetal in natura e/ou minimamente processados (BRASIL, 2014). Mais especificamente, o Ministério da Saúde preconiza que alimentos como frutas, hortaliças e feijões sejam reconhecidos como marcadores de alimentação saudável (BRASIL, 2015). Nesse sentido, a Lei n. 11.947/2009, que regulamenta o PNAE, se apresenta como um importante instrumento para a oferta de uma alimentação adequada, especialmente quando institui, no artigo 14, que pelo menos $30 \%$ do recurso repassado pelo Fundo Nacional de Desenvolvimento da Educação (FNDE) do Ministério da Educação (MEC) às Entidades Executoras (EE) sejam utilizados na compra de alimentos oriundos da agricultura familiar (BRASIL, 2009; BRASIL 2014). Ademais, ao ofertar uma alimentação adequada aos escolares, o PNAE se materializa como política pública saudável, interferindo na formação de hábitos alimentares promotores de saúde.

Assim, a presença da agricultura familiar na execução do PNAE pode colaborar com uma maior variedade de frutas e outros vegetais na alimentação dos escolares. Ainda, deve-se levar em consideração que os produtos da agricultura familiar são potencialmente mais frescos e normalmente mais bem aceitos pelos estudantes. Merece destaque também a ponderação de que a prioridade de aquisição dos produtos produzidos localmente fortalece os agricultores familiares e a economia da região, além de incentivar práticas ambientalmente sustentáveis (BRASIL, 2016).

Além disso, a Resolução CD/FNDE n. 26/2013 determina que a elaboração dos cardápios escolares deverá contemplar a oferta mínima de três porções de frutas e hortaliças por semana (200g/aluno/semana) e que a composição das refeições deverá atender a um mínimo que varia entre $20 \%$ e $70 \%$ das referências nutricionais diárias, conforme a etapa (educação infantil/creches ou demais níveis da educação básica), a 
Potencial contribuição da agricultura familiar para

Gisele Assumpção Vieira uma alimentação escolar saudável no estado de Carla Rosane Paz Arruda Teo Santa Catarina no período de 2015 a 2017

Roberta Lamonatto Taglietti

modalidade (educação indígena e quilombola ou demais modalidades) e a jornada (parcial ou integral) de ensino (BRASIL,2013).

Diante desse contexto, o objetivo deste estudo foi analisar a contribuição dos alimentos da agricultura familiar presentes nos editais de chamada pública dos municípios catarinenses para a alimentação escolar quanto à oferta de marcadores alimentares saudáveis, no período de 2015 a 2017.

\section{Metodologia}

\section{Tipo de estudo}

Trata-se de uma pesquisa documental de abordagem quantitativa e caráter analítico, desenvolvida mediante documentos disponibilizados em livre acesso por meio eletrônico.

\section{Fontes de dados}

Foram utilizados os seguintes documentos como fontes de dados: editais de chamada pública para compra de alimentos da agricultura familiar destinados à alimentação escolar divulgados nos sites das prefeituras dos municípios catarinenses no período de 2015 a 2017; relatórios anuais obtidos no site do Instituto Nacional de Estudos e Pesquisas Educacionais Anísio Teixeira (INEP), para o período de 2015 a 2017, referentes ao Censo Escolar dos municípios que tenham publicado editais incluídos nesta pesquisa (INEP, 2015; 2016; 2017).

Todas as fontes documentais utilizadas neste estudo são de acesso público irrestrito.

\section{Critério de inclusão dos editais}

Dado o objetivo do estudo - analisar a potencial contribuição da agricultura familiar para uma alimentação escolar saudável -, o critério de inclusão compreendeu os editais de chamada pública dos municípios Catarinenses, de compra da agricultura familiar para a alimentação escolar nos anos de 2015 a 2017, que tenham solicitado pelo menos um alimento dos grupos definidos pelo Ministério da Saúde (BRASIL, 2015) como marcadores de alimentação saudável: frutas, hortaliças e feijões. 
Potencial contribuição da agricultura familiar para uma alimentação escolar saudável no estado de Santa Catarina no período de 2015 a 2017
Gisele Assumpção Vieira

Carla Rosane Paz Arruda Teo

Roberta Lamonatto Taglietti

A escolha pela avaliação dos editais do triênio 2015-2017 se deve ao fato de que este estudo é parte de uma pesquisa matricial longitudinal, que já analisou dados similares relativos ao período de 2012 a 2014 (TEO, et. al., 2019).

\section{Coleta e organização dos dados}

A busca dos editais de chamada pública ocorreu no banco documental do "Observatório da Aquisição de Alimentos da Agricultura Familiar para a Alimentação Escolar em Santa Catarina", vinculado ao "Núcleo de Estudos e Pesquisas em Alimentação e Nutrição (NEPAL)" da Universidade Comunitária da Região de Chapecó.

Inicialmente, foram selecionados os editais de interesse para o estudo, conforme período e critério de inclusão previamente definidos. Destes documentos, foram coletados, codificados e armazenados dados, compondo-se um banco em forma de planilha eletrônica, no programa Microsoft Excel ${ }^{\circledR}$, com informações relativas a mesorregião, município, item alimentar (nome do alimento) e quantidade em gramas (g) dos alimentos. Pontua-se que não foram considerados para este estudo os sucos e as polpas de frutas, em virtude de que a Resolução CD/FNDE n. 26/2013 (BRASIL, 2013) estabelece que estes alimentos não devem ser considerados no cômputo das porções de frutas.

Para os alimentos solicitados nos editais e cujas quantidades estavam expressas em caixas ou unidades foram utilizadas informações disponíveis no site da Central de Abastecimento do Estado de Santa Catarina (CEASA/SC, 2018) para a conversão em gramas.

Posteriormente, para estimar o peso líquido desses alimentos, foi aplicado (quando apropriado, especialmente para frutas e hortaliças) o Índice de Parte Comestível (utilizouse a tabela de Índice de Parte Comestível (IPC) desenvolvida no Laboratório Dietético da Universidade Comunitária da Região de Chapecó, de modo a estimar a fração comestível derivada daquela listada na chamada pública para aquisição. Após a determinação dessas quantidades líquidas, o peso (em gramas) foi dividido pelo número de dias letivos no ano (200) e, a seguir, pelo alunado atendido (conforme os Censos Escolares anuais do INEP), chegando-se à quantidade per capita líquida estimada desses alimentos fornecidos pela agricultura familiar para a alimentação escolar (figura 1). 
Potencial contribuição da agricultura familiar para

Gisele Assumpção Vieira uma alimentação escolar saudável no estado de

Figura 1: Fluxograma de determinação do per capita líquido

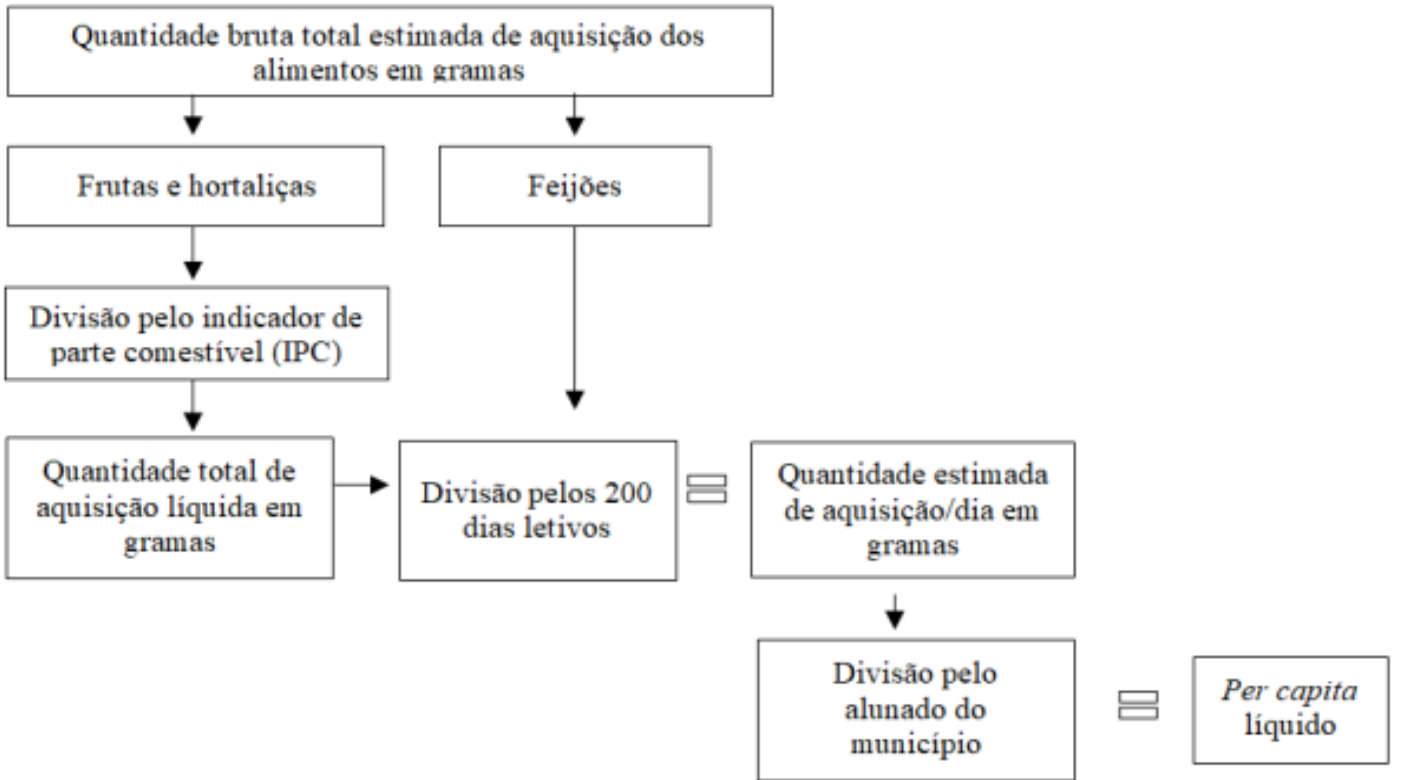

Fonte: Elaboração do grupo de pesquisa NEPAL, 2018.

Subsequentemente, as quantidades per capita líquidas estimadas foram somadas por grupos de alimentos (marcadores alimentares saudáveis), quais sejam: frutas, hortaliças e feijões. Pontua-se que variedades diferentes de um mesmo alimento foram consideradas como um só tipo de alimento, como no exemplo: banana caturra, banana prata $=$ banana; pepino salada, pepino japonês $=$ pepino .

A seguir, foi construído um segundo banco de dados, também no programa Microsoft Excel ${ }^{\circledR}$, constituído pelas seguintes variáveis: mesorregião, município, ano, per capita diário de frutas, per capita diário de hortaliças, per capita diário de frutas e hortaliças (somado), per capita diário de feijões, per capita diário de alimentos saudáveis (somado), variedade de frutas, variedade de hortaliças, variedade de feijões, percentual de adequação do per capita semanal de frutas e hortaliças (estimado por extrapolação a partir do per capita diário de frutas e hortaliças - somado) à recomendação da Resolução CD/FNDE n. 26/2013 do FNDE, que é de 200g.

\section{Análise dos dados}

Foi realizada análise descritiva dos dados (média e desvio padrão). Para verificar a existência de correlação entre as diversas variáveis do estudo (per capita diário de frutas, per capita diário de hortaliças, per capita diário de feijões, variedade de frutas, variedade de hortaliças, variedade de feijões, percentual de adequação do per capita 
Potencial contribuição da agricultura familiar para uma alimentação escolar saudável no estado de Santa Catarina no período de 2015 a 2017
Gisele Assumpção Vieira

Carla Rosane Paz Arruda Teo

Roberta Lamonatto Taglietti

semanal de frutas e hortaliças à recomendação de consumo do FNDE) foi aplicado o teste de correlação de Pearson. O nível de significância adotado foi de 5\% e os dados foram analisados no programa Statistical Package for the Social Sciencies (SPSS), versão 24.0.

\section{Contexto do estudo}

O estado de Santa Catarina possui 295 municípios distribuídos em seis mesorregiões: Vale do Itajaí, Grande Florianópolis, Sul Catarinense, Norte Catarinense, Serrana e Oeste Catarinense (tabela 1).

Tabela 1: Características sociodemográficas do estado de Santa Catarina por mesorregião.

\begin{tabular}{|c|c|c|c|c|c|c|c|}
\hline Indicadores & $\begin{array}{l}\text { Vale do } \\
\text { Itajaí }\end{array}$ & $\begin{array}{c}\text { Grande } \\
\text { Florianópolis }\end{array}$ & $\begin{array}{c}\text { Sul } \\
\text { catarinense }\end{array}$ & $\begin{array}{c}\text { Norte } \\
\text { catarinense }\end{array}$ & Serrana & $\begin{array}{c}\text { Oeste } \\
\text { catarinense }\end{array}$ & $\begin{array}{c}\text { Santa } \\
\text { Catarina }\end{array}$ \\
\hline $\begin{array}{l}\text { Número de } \\
\text { municípios }\end{array}$ & 54 & 21 & 46 & 26 & 30 & 118 & 295 \\
\hline $\begin{array}{l}\text { População ( }{ }^{\circ} \\
\text { de } \\
\text { habitantes })^{1}\end{array}$ & $1.799,940$ & $1.167,379$ & $1.022,269$ & $1.384,571$ & 415.191 & $1.286,144$ & $7.075,494$ \\
\hline $\begin{array}{l}\text { População } \\
\text { rural2 (mil } \\
\text { habitantes) }\end{array}$ & 186.900 & 78.300 & 171.900 & 148.900 & 74.300 & 340.100 & $1.000,4$ \\
\hline $\begin{array}{l}\text { Número de } \\
\text { alunos }^{3}\end{array}$ & 213.829 & 88.917 & 94.313 & 160.811 & 45.544 & 140.933 & 744.347 \\
\hline
\end{tabular}

${ }^{1}$ IBGE (estimativa 2018).

Fonte: Elaboração das autoras (2019).

${ }^{2}$ IBGE (2010).

${ }^{3}$ Número de alunos matriculados na rede municipal de educação básica (INEP, 2017).

Em termos econômicos, Santa Catarina tem expressiva participação da agricultura familiar, que responde por $67 \%$ do valor bruto total de produção dos estabelecimentos agropecuários do estado, ocupando, dessa forma, a terceira posição no cenário nacional, atrás apenas dos estados do Rio Grande do Sul e Paraná (MARCONDES, 2016).

Como característica, a agricultura familiar catarinense apresenta uma vasta diversificação de sua base produtiva, combinando produtos de origem vegetal com a criação de animais (MIOR et al., 2014).

Segundo o Censo Agropecuário 2017, 77\% dos estabelecimentos (aproximadamente 3,9 milhões) são classificados como agricultura familiar no Brasil, representando uma área de cultivo de 80,9 milhões de hectares, o que corresponde a 23\% da área de todos os estabelecimentos agropecuários do País. Na região Sul, Santa Catarina se destaca pela maior proporção de área ocupada pela agricultura familiar, seguido por Rio Grande do Sul e Paraná (IBGE, 2017). 
Potencial contribuição da agricultura familiar para uma alimentação escolar saudável no estado de Santa Catarina no período de 2015 a 2017
Gisele Assumpção Vieira

Carla Rosane Paz Arruda Teo

Roberta Lamonatto Taglietti

O estado também é um importante produtor de frutas, com destaque para a produção de maçãa, banana, uva, pêssego, maracujá, laranja e frutas de caroço. Trata-se de uma atividade produtiva que tem um peso significativo na geração de renda de agricultores familiares em Santa Catarina (GOULART JUNIOR; REITER; MONDARDO, 2016).

\section{Resultados e discussão}

Inicialmente, no período de abrangência do estudo, foram coletados 661 editais de chamada pública para a compra de alimentos da agricultura familiar para o PNAE. Da aplicação dos critérios definidos para este estudo, foram excluídas 36 chamadas públicas que não contemplavam marcadores alimentares saudáveis, conforme definidos pelo Ministério da Saúde (BRASIL, 2015). Desse modo, foram analisados 625 editais, sendo que 147 municípios publicaram 31,4\% ( $\mathrm{n}=196)$ daqueles selecionados no ano de 2015, 165 municípios publicaram 35,3\% $(\mathrm{n}=221)$ dos editais do ano de 2016 e 186 municípios publicaram 33,3\% ( $\mathrm{n}=208)$ dos editais de 2017 (tabela 2).

Tabela 2: Distribuição dos editais de chamada pública divulgados com marcadores alimentares saudáveis por mesorregião de Santa Catarina, Brasil, 2015-2017.

\begin{tabular}{lcccccc}
\hline \multicolumn{1}{c}{ Mesorregião } & \multicolumn{2}{c}{$\mathbf{2 0 1 5}$} & \multicolumn{2}{c}{$\mathbf{2 0 1 6}$} & \multicolumn{2}{c}{$\mathbf{2 0 1 7}$} \\
\hline & Mun $^{1}$ & CP $^{2}$ & Mun $^{1}$ & CP $^{2}$ & Mun $^{1}$ & CP $^{2}$ \\
Vale do Itajaí & 27 & 35 & 30 & 40 & 31 & 33 \\
Grande Florianópolis & 7 & 8 & 9 & 11 & 13 & 15 \\
Sul Catarinense & 15 & 17 & 13 & 14 & 20 & 22 \\
Norte Catarinense & 17 & 24 & 18 & 27 & 17 & 22 \\
Serrana & 15 & 20 & 13 & 16 & 16 & 17 \\
Oeste Catarinense & 66 & 92 & 82 & 113 & 89 & 99 \\
Santa Catarina & 147 & 196 & 165 & 221 & 186 & 208 \\
\hline
\end{tabular}

Fonte: Elaboração das autoras (2019).

${ }^{1}$ Número de Municípios por mesorregião que publicaram editais de chamada pública com marcadores alimentares saudáveis.

${ }^{2}$ Número de chamadas públicas (CP) selecionadas para estudo por mesorregião.

Conforme a metodologia descrita, foram estimadas as quantidades médias (em gramas) de aquisição per capita líquida, no período de 2015 a 2017, de frutas, hortaliças e feijões (tabela 3).

Todas as mesorregiões do estado tiveram a média semanal per capita estimada de frutas e hortaliças acima dos 200g semanais recomendados pela Resolução CD/FNDE n. 26/2013 (BRASIL, 2013), destacando-se a Serrana como a que apresentou a mais elevada média per capita destes alimentos, ultrapassando em $82,75 \%$ a recomendação do FNDE. 
Potencial contribuição da agricultura familiar para uma alimentação escolar saudável no estado de Santa Catarina no período de 2015 a 2017
Gisele Assumpção Vieira

Carla Rosane Paz Arruda Teo

Roberta Lamonatto Taglietti

Isso indica que a aquisição de alimentos da agricultura familiar pode atender à demanda das diferentes mesorregiões do estado de Santa Catarina para o cumprimento da recomendação do FNDE quanto à oferta de frutas e hortaliças, o que evidencia sua contribuição à oferta de alimentação escolar adequada e saudável.

Tabela 3: Quantidades per capita líquidas (em gramas) estimadas de frutas, hortaliças e feijões por mesorregião, Santa Catarina, Brasil, 2015-2017.

\begin{tabular}{|c|c|c|c|c|c|c|}
\hline Mesorregião & $\begin{array}{c}\text { Per capita } \\
\text { diário } \\
\text { F (g) }\end{array}$ & $\begin{array}{c}\text { Per capita } \\
\text { diário } \\
\text { H }(\mathrm{g})^{2}\end{array}$ & $\begin{array}{c}\text { Per capita } \\
\text { diário } \\
\text { FH }(g)^{3}\end{array}$ & $\begin{array}{c}\text { Per capita } \\
\text { semanal } \\
\text { FH }(g)^{3}\end{array}$ & $\begin{array}{c}\text { Per capita } \\
\text { diário } \\
\mathrm{Fj}(\mathrm{g})^{4}\end{array}$ & $\begin{array}{c}\text { Per capita } \\
\text { diário } \\
\text { alimentos } \\
\text { saudáveis }(\mathbf{g})^{5}\end{array}$ \\
\hline & $\mathrm{M}^{6} \pm \mathrm{DP}^{7}$ & $\mathrm{M}^{6} \pm \mathrm{DP}^{7}$ & $\mathrm{M}^{6} \pm \mathrm{DP}^{7}$ & $\mathrm{M}^{6} \pm \mathrm{DP}^{7}$ & $\mathrm{M}^{6} \pm \mathrm{DP}^{7}$ & $\mathrm{M}^{6} \pm \mathrm{DP}^{7}$ \\
\hline Vale do Itajaí & $26,8 \pm 27,0$ & $29,6 \pm 21,2$ & $56,4 \pm 43,3$ & $282,0 \pm 217,1$ & $2,8 \pm 3,5$ & $59,2 \pm 45,1$ \\
\hline $\begin{array}{l}\text { Grande } \\
\text { Florianópolis }\end{array}$ & $31,0 \pm 26,6$ & $20,6 \pm 15,3$ & $51,5 \pm 35,3$ & $257,5 \pm 176,4$ & $2,0 \pm 2,5$ & $53,5 \pm 36,5$ \\
\hline $\begin{array}{l}\text { Sul } \\
\text { Catarinense }\end{array}$ & $28,5 \pm 27,6$ & $20,8 \pm 9,4$ & $49,3 \pm 32,7$ & $246,5 \pm 163,4$ & $3,2 \pm 3,1$ & $52,5 \pm 33,9$ \\
\hline $\begin{array}{l}\text { Norte } \\
\text { Catarinense }\end{array}$ & $24,5 \pm 19,2$ & $26,6 \pm 16,3$ & $51,1 \pm 28,6$ & $255,5 \pm 142,8$ & $3,0 \pm 3,0$ & $54,1 \pm 30,0$ \\
\hline Serrana & $29,8 \pm 32,7$ & $43,3 \pm 33,7$ & $73,1 \pm 61,9$ & $365,5 \pm 309,6$ & $6,5 \pm 6,1$ & $79,6 \pm 64,9$ \\
\hline $\begin{array}{l}\text { Oeste } \\
\text { Catarinense }\end{array}$ & $27,0 \pm 29,4$ & $22,0 \pm 22,4$ & $49,0 \pm 47,0$ & $245,0 \pm 235,0$ & $2,0 \pm 3,0$ & $51,0 \pm 48,9$ \\
\hline $\begin{array}{l}\text { Santa } \\
\text { Catarina }\end{array}$ & $27,3 \pm 28,0$ & $25,5 \pm 22,5$ & $52,8 \pm 44,9$ & $264,2 \pm 224,3$ & $2,8 \pm 3,7$ & $55,6 \pm 46,9$ \\
\hline
\end{tabular}

Fonte: Elaboração das autoras (2019).

${ }^{1}$ Quantidade (em gramas) de frutas.

${ }^{2}$ Quantidade (em gramas) de hortaliças.

${ }^{3}$ Quantidades somadas (em gramas) de frutas e hortaliças.

${ }^{4}$ Quantidade (em gramas) de feijões.

${ }^{5}$ Quantidades somadas (em gramas) dos marcadores alimentares saudáveis (frutas, hortaliças e feijões).

${ }^{6}$ Média do per capita no período de estudo.

${ }^{7}$ Desvio padrão.

Observou-se, também, correlação positiva entre a adequação à recomendação do FNDE e os per capitas de frutas $(r=0,912 ; \mathrm{p}<0,01)$ e de hortaliças $(r=0,859 ; \mathrm{p}<0,01)$ separadamente (tabela 4). Sugere-se que esse resultado, por mais que pareça uma obviedade, indica que tanto a aquisição de frutas como a de hortaliças contribuem para a adequação à recomendação do FNDE, ou seja, a adequação vem sendo atendida tanto pela oferta de frutas como pela de hortaliças. Corrobora esse achado a correlação constatada entre as quantidades médias per capita de frutas e de hortaliças $(r=0,574$; p<0,01) (tabela 4), o que evidencia que à medida que os municípios demandam frutas da agricultura familiar, também demandam hortaliças, isto é, a demanda não está concentrada em um destes tipos de alimentos saudáveis, garantindo diversidade na alimentação escolar. 
Potencial contribuição da agricultura familiar para uma alimentação escolar saudável no estado de Santa Catarina no período de 2015 a 2017
Gisele Assumpção Vieira

Carla Rosane Paz Arruda Teo

Roberta Lamonatto Taglietti

Tabela 4: Correlação entre as variáveis per capita de frutas, per capita de hortaliças, per capita de feijões, variedade de frutas, variedade de hortaliças, variedade de feijões e adequação à recomendação da Resolução CD/FNDE n. 26/2013 do FNDE para oferta de $200 \mathrm{~g} / \mathrm{semana}$ de frutas e hortaliças.

\begin{tabular}{lccccccc}
\hline \multicolumn{1}{c}{ Variáveis } & PcF & PcH & PcFj & VarF & VarH & VarFj & \%ADE \\
\hline PcF & $1^{*}$ & & & & & & \\
PcH & $0,574^{*}$ & $1^{*}$ & & & & & \\
PcFj & $0,365^{*}$ & $0,596^{*}$ & $1^{*}$ & & & & \\
VarF & $0,533^{*}$ & $0,295^{*}$ & $0,238^{*}$ & $1^{*}$ & & & \\
VarH & $0,316^{*}$ & $0,500^{*}$ & $0,282^{*}$ & $0,620^{*}$ & $1^{*}$ & & \\
VarFj & $0,221^{*}$ & $0,241^{*}$ & $0,535^{*}$ & $0,429^{*}$ & $0,445^{*}$ & $1^{*}$ & \\
\%ADE & $0,912^{*}$ & $0,859^{*}$ & $0,526^{*}$ & $0,480^{*}$ & $0,447^{*}$ & $0,258^{*}$ & $1^{*}$ \\
\hline
\end{tabular}

Fonte: Elaboração das autoras (2019).

$\mathrm{PcF}=$ per capita frutas; $\mathrm{PcH}=$ per capita de hortaliças $\mathrm{PcFj}=$ per capita feijões; $\mathrm{VarF}=$ variedade de frutas; $\mathrm{VarH}=$ variedade de hortaliças; $\mathrm{VarFj}=$ variedade de feijões; $\% \mathrm{ADE}=$ percentual adequação à recomendação do FNDE para oferta de $200 \mathrm{~g} / \mathrm{semana}$ de frutas e hortaliças.

*Correlação de Pearson foi significativa no nível 0,01.

Embora seja positivo que as aquisições estejam adequadas à recomendação do FNDE, cabe ponderar que a orientação para a oferta mínima de três porções de frutas e hortaliças por semana (200g/aluno/semana) pode ser tida como baixa, ao se levar em consideração que a Organização Mundial de Saúde (OMS) preconiza que sejam consumidos 400g ao dia desses alimentos (WHO, 2002). Nesse caso, o recomendado pelo programa equivaleria, em média, a apenas $10 \%$ do que propõe a OMS para um período estimado de permanência na escola de, no mínimo, um turno diário.

A esse respeito cabe destacar que a Resolução CD/FNDE n. 6, publicada em 8 de maio de 2020, altera a recomendação de oferta de frutas e hortaliças, que passa a ser de $280 \mathrm{~g} /$ aluno/semana para os estudantes que permanecem na escola em período parcial e de $520 \mathrm{~g} /$ aluno/semana para os que frequentam a escola em período integral. Contudo, mesmo com essa alteração, a oferta de frutas e hortaliças preconizada pelo FNDE ainda representa apenas $14 \%$ da recomendação diária da OMS para os estudantes de período parcial e $26 \%$ para os de período integral.

Isso significa que os escolares precisam consumir entre 74 a $86 \%$ da recomendação da OMS para uma alimentação saudável nos turnos diários em que não estão na escola, o que não parece contemplar uma distribuição dietética que favoreça o consumo destes alimentos nos níveis propostos.

Assim, há de se pensar que a escola poderia contribuir mais expressivamente com a oferta de frutas e hortaliças, de forma a se aproximar ou, até mesmo, se equivaler à recomendação da OMS, já que é no ambiente escolar que os alunos permanecem durante 
Potencial contribuição da agricultura familiar para uma alimentação escolar saudável no estado de Santa Catarina no período de 2015 a 2017
Gisele Assumpção Vieira Carla Rosane Paz Arruda Teo Roberta Lamonatto Taglietti

relevante parte de seu dia, a depender da jornada de ensino, que pode ser parcial ou integral. Além disso, uma oferta maior de frutas e hortaliças estaria mais condizente com a diretriz da Lei n. 11.947/2009, que estabelece o emprego de alimentação saudável e adequada.

Neste sentido, apesar de a alimentação escolar não poder ser responsabilizada pelo atendimento integral da recomendação da OMS, é importante considerar que a oferta indicada pelo FNDE fica muito aquém da recomendação diária estabelecida internacionalmente como suficiente para a prevenção de doenças e a manutenção da saúde. Essa ponderação é ainda mais pertinente em se tratando de escolares de período integral e/ou em condição de vulnerabilidade social, situações em que a alimentação escolar assume protagonismo na oferta alimentar, que deve ser proporcional ao tempo de permanência na escola conforme as diretrizes do PNAE.

Além disso, iniciativas como a compra institucional de alimentos da agricultura familiar configuram-se como ações de SAN e de garantia do Direito Humano à Alimentação Adequada (DHAA) - tanto para os escolares quanto para os agricultores e de promoção do desenvolvimento sustentável (SCHWARTZMAN et al., 2017a). Ou seja, a compra institucional de alimentos promovida por políticas públicas, como o Programa de Aquisição de Alimentos (PAA) e o PNAE, garante mercado consumidor e escoamento de produtos da agricultura familiar e, pari passu, oportuniza acesso alimentar e desenvolvimento de hábitos saudáveis aos estudantes, com potencial de alcançar suas famílias e a comunidade escolar de forma ampliada.

A esse propósito, Teo e Monteiro (2012) sugerem a oferta mínima de uma porção de frutas e hortaliças por refeição escolar como forma de contribuir para uma alimentação escolar mais saudável (TEO; MONTEIRO, 2012). Tal medida poderia trazer mais benefícios à saúde dos escolares, principalmente se for considerado que é na escola que muitos realizam se não a única, pelo menos a melhor refeição diária (STURION et al., 2005; BEZERRA, 2009; FREITAS et al., 2013). Dessa forma, ao ofertar alimentos mais saudáveis, como frutas e hortaliças, a escola pode se apresentar também como um local propicio à formação de hábitos alimentares entre os estudantes, já que o ambiente escolar representa de fato um espaço de aprendizagem e de construções de práticas saudáveis (TEO et al., 2016).

Em termos nutricionais, as frutas são excelentes fontes de vitaminas, minerais, fibras e de vários compostos que contribuem para a prevenção de muitas doenças, assim 
Potencial contribuição da agricultura familiar para uma alimentação escolar saudável no estado de Santa Catarina no período de 2015 a 2017
Gisele Assumpção Vieira Carla Rosane Paz Arruda Teo Roberta Lamonatto Taglietti

como as hortaliças, que de um modo geral fornecem muitos nutrientes em quantidades relativamente pequenas de calorias, o que contribui para a prevenção da obesidade e de outras doenças crônicas associadas ao consumo excessivo de energia, como diabetes e doenças do coração. Ademais, as hortaliças também contêm antioxidantes que protegem de alguns tipos de câncer. Tanto as frutas como as hortaliças devem, portanto, ser consumidas regularmente, por serem consideradas alimentos saudáveis (BRASIL, 2014).

Estudos têm demonstrado que, embora as Entidades Executoras priorizem a aquisição de frutas e hortaliças nas compras da agricultura familiar (TOYOYOSHI et al., 2013; BARONE et al., 2016; FURH; TRICHES, 2017; ROCKETT et al., 2019), o consumo destes alimentos pelos escolares ainda é baixo. O estudo de Costa, Vasconcelos e Corso (2012) corrobora essas ponderações quando, ao estimar a frequência do consumo de frutas e hortaliças por 4.964 escolares do ensino fundamental em Santa Catarina, constata que apenas $2,7 \%$ deles apresentaram consumo regular destes alimentos (cinco vezes ao dia), enquanto $26,6 \%$ não chegaram a consumi-los sequer uma vez ao dia (COSTA; VASCONCELOS; CORSO, 2012).

Mesmo diante de tais evidências, o fato de os alunos estarem em um ambiente que oferte alimentos segundo as diretrizes do PNAE e com prioridade à agricultura familiar pode contribuir para que esses estudantes tendam a consumir menos alimentos considerados não saudáveis, como evidenciado por NOLL et al. (2019), em estudo com 102.072 adolescentes brasileiros com idade entre 11 e 19 anos matriculados no $9^{\circ}$ ano do ensino fundamental. Os resultados obtidos pelos autores indicam que a presença do PNAE na escola resulta em menor probabilidade de que os estudantes consumam alimentos ultraprocessados e refrigerantes, se comparados com os que frequentam escolas não contempladas pelo PNAE (NOLL et al., 2019).

Isso reforça que a aquisição de alimentos da agricultura familiar pode se apresentar como uma estratégia de contraposição à tendência mundial de ocidentalização da cultura alimentar, garantindo o acesso a produtos mais frescos e com maior densidade nutricional e a refeições escolares com maior variedade (FUHR; TRICHES, 2017).

Observou-se, também, que o per capita de feijões nas mesorregiões catarinenses se apresentou abaixo da recomendação para o consumo destes alimentos, que é de aproximadamente 40g/dia (BRASIL, 2008) (tabela 3). Uma hipótese a ser considerada para o baixo per capita de feijões derivado das chamadas públicas analisadas é que as Entidades Executoras podem estar demandando estes alimentos de empresas 
Potencial contribuição da agricultura familiar para uma alimentação escolar saudável no estado de Santa Catarina no período de 2015 a 2017
Gisele Assumpção Vieira Carla Rosane Paz Arruda Teo Roberta Lamonatto Taglietti

convencionais por meio de processo licitatório, e não da agricultura familiar catarinense. Outra hipótese é que as escolas podem não incluir diariamente o feijão nos cardápios escolares, como apontam Martinelli et al. (2014) que, ao caracterizarem a composição dos cardápios escolares de três municípios na região Sul do Brasil (Paraná, Santa Catarina e Rio Grande do Sul), no ano de 2011, identificaram que a combinação feijão e arroz esteve presente em apenas um dia do cardápio mensal do município de Santa Catarina (MARTINELLI et al., 2014).

Pondera-se, ainda, que o Estado do Paraná (da região Sul) lidera o ranking dos principais produtores nacionais de feijão, com 18,9\% do total produzido. Os agricultores familiares respondem por $70 \%$ da produção nacional. Em Santa Catarina, o feijão é cultivado em todas as regiões, com destaque para os Planaltos Norte e Serrano, o Oeste e o Litoral Sul (EPAGRI, 2018). Ainda, de acordo com o Centro de Socioeconomia e Planejamento Agrícola (Epagri/Cepa), a área de produção de feijão vem diminuindo em Santa Catarina, devido a oscilações de mercado próprias do produto, associadas à diminuição da mão de obra disponível e ao desconhecimento de tecnologias de baixo custo e acessíveis ao pequeno produtor (EPAGRI, 2018).

Tradicionalmente, o feijão, juntamente com o arroz, compõe a base alimentar do brasileiro, porém, nas últimas décadas, como parte do processo de transição nutricional em progresso no País, tem ocorrido uma diminuição do consumo destes alimentos pelas famílias e, em paralelo, um aumento do consumo de ultraprocessados (refrigerantes, bebidas lácteas, embutidos, entre outros), conforme aponta a Pesquisa de Orçamento Familiar (POF) realizada nos anos de 2008 e 2009 (IBGE, 2010). Essa transição nutricional é, seguramente, uma questão multifatorial, cabendo destacar, entre os prováveis fatores causais implicados, a melhora de renda das famílias e a consequente ampliação do acesso a alimentos industrializados. Ademais, outros fatores contribuintes para este fenômeno são a urbanização do país (na década de 1950 a população rural representava $66 \%$ e, atualmente, o país tem $80 \%$ de sua população radicada nas cidades) e a inserção da mulher no mercado de trabalho, já que ela, historicamente, assume o papel de responsável pela preparação dos alimentos no domicílio (BATISTA FILHO; RISSIN, 2003; MENDONÇA; ANJOS, 2004).

A PeNSE 2015, realizada com estudantes do $9^{\circ}$ ano do ensino fundamental das capitais brasileiras, revelou redução de $10 \%$ na proporção de alunos com frequência de consumo de feijão igual ou superior a cinco dias na semana, associada ao crescimento de 
$51,3 \%$ daqueles que referiram não ter consumido a leguminosa na semana anterior à da pesquisa (IBGE, 2016).

Os feijões são importantes fontes de proteínas, vitaminas do complexo B e minerais como ferro, zinco e cálcio, além de serem ricos em fibras. Além disso, a quantidade de calorias por grama proporciona maior saciedade, prevenindo a ingestão excessiva de alimentos (BRASIL, 2014). Considerando os fatores nutricionais benéficos à saúde, reforça-se que a escola pode exercer um importante papel para o consumo de feijões entre crianças e adolescentes, ao incluir com maior frequência e regularidade esses alimentos nos cardápios escolares como forma de incentivar o seu consumo, que reconhecidamente tem diminuído no Brasil.

Prosseguindo, apesar de se considerar que o per capita de feijões, neste estudo, foi baixo, um resultado favorável a ser destacado é a constatação de correlação positiva entre o per capita de feijões e os per capitas de hortaliças $(r=0,596 ; \mathrm{p}<0,05)$ e de frutas $(\mathrm{r}=0,365 ; \mathrm{p}<0,05)$. Esse achado parece corroborar a hipótese de que a demanda apresentada pelos municípios das diferentes mesorregiões do estado para a agricultura familiar não está concentrada apenas em um dos marcadores alimentares saudáveis.

Quanto à variedade dos alimentos presentes nas chamadas públicas analisadas neste estudo, foram observadas 48 variedades no grupo das hortaliças, 35 variedades no das frutas e nove no grupo dos feijões (quadro 1).

Quadro 1: Variedade dos alimentos marcadores saudáveis presentes nas chamadas públicas analisadas, de acordo com o grupo alimentar, Santa Catarina, Brasil 2015-

$$
2017 .
$$

\begin{tabular}{|c|c|c|}
\hline Hortaliça & Frutas & Feijōes \\
\hline $\begin{array}{l}\text { Abóbora cabotiá, abóbora comum } \\
\text { moranga, abóbora de pescoço, } \\
\text { abobrinha italiana, açafrão, acelga, } \\
\text { agrião, alecrim, alface, alho, alho } \\
\text { poró, almeirão, berinjela, beterraba, } \\
\text { brócolis, cebola, cebolinha, cenoura, } \\
\text { cheiro verde, chicória, chuchu, } \\
\text { coentro, couve flor, couve manteiga, } \\
\text { espinafre, hortelã, manjericão, } \\
\text { manjerona, mostarda, nabo, } \\
\text { orapronobis, orégano, pepino, } \\
\text { pimenta, pimentão amarelo, pimentão } \\
\text { verde, pimentão vermelho, pinhão, } \\
\text { quiabo, rabanete, radite, repolho } \\
\text { branco, repolho roxo, rúcula, salsa, } \\
\text { salsão,tomate, vagem. }\end{array}$ & $\begin{array}{l}\text { Abacate, abacaxi, } \\
\text { ameixa, amora, araçá, banana, } \\
\text { banana passa, bergamota, caqui, } \\
\text { carambola, coco ralado, figo, fruta } \\
\text { do conde, goiaba branca, goiaba } \\
\text { vermelha, jabuticaba, kiwi, } \\
\text { laranja, lima, limão, maçă, } \\
\text { mamão, manga, maracuja,, } \\
\text { melancia, melão, mirtilo, } \\
\text { morango, nectarina, pera, } \\
\text { pêssego, physalis, tangerina } \\
\text { poncã, uva comum. }\end{array}$ & $\begin{array}{l}\text { Ervilha desidratada, ervilha } \\
\text { fresca, fava, feijão branco, } \\
\text { feijão carioca, feijão preto, } \\
\text { feijão vermelho, grão de bico, } \\
\text { lentilha. }\end{array}$ \\
\hline
\end{tabular}

Fonte: Elaboração das autoras (2019). 
Potencial contribuição da agricultura familiar para uma alimentação escolar saudável no estado de Santa Catarina no período de 2015 a 2017
Gisele Assumpção Vieira Carla Rosane Paz Arruda Teo Roberta Lamonatto Taglietti

Considerando uma análise por mesorregião, na média dos três anos, a Serrana se destacou quanto às variedades de hortaliças $(15,9 \pm 7,3)$ e de feijões $(1,4 \pm 0,9)$. Já a mesorregião Norte, com resultados próximos aos da Serrana, pode ser destacada quanto às variedades de frutas $(5,4 \pm 4,4)$ e de hortaliças $(14,5 \pm 6,2)$ (gráfico 1).

Especificamente na mesorregião Serrana, os municípios de Curitibanos e Lages estão entre os três principais produtores de feijão do estado. Essa mesorregião também se destaca no cultivo de algumas espécies de frutas como pêra, uvas e maçã. O Norte Catarinense, também se destaca na produção de frutas (em especial banana e tangerina) (GOULART JUNIOR; REITER; MONDARDO, 2016; EPAGRI/CEPA, 2018). Desse modo, sugere-se que a vocação agrícola das diferentes mesorregiões interfere na diversidade e na variedade das aquisições da agricultura familiar para a alimentação escolar. Reconhecer essa relação pode ser um elemento dinamizador do desenvolvimento da agricultura familiar no estado, com vistas a qualificar sua contribuição para a oferta de alimentação escolar adequada e saudável.

Gráfico 1: Variedade de alimentos marcadores saudáveis por mesorregião, Santa Catarina, Brasil, 2015-2017.

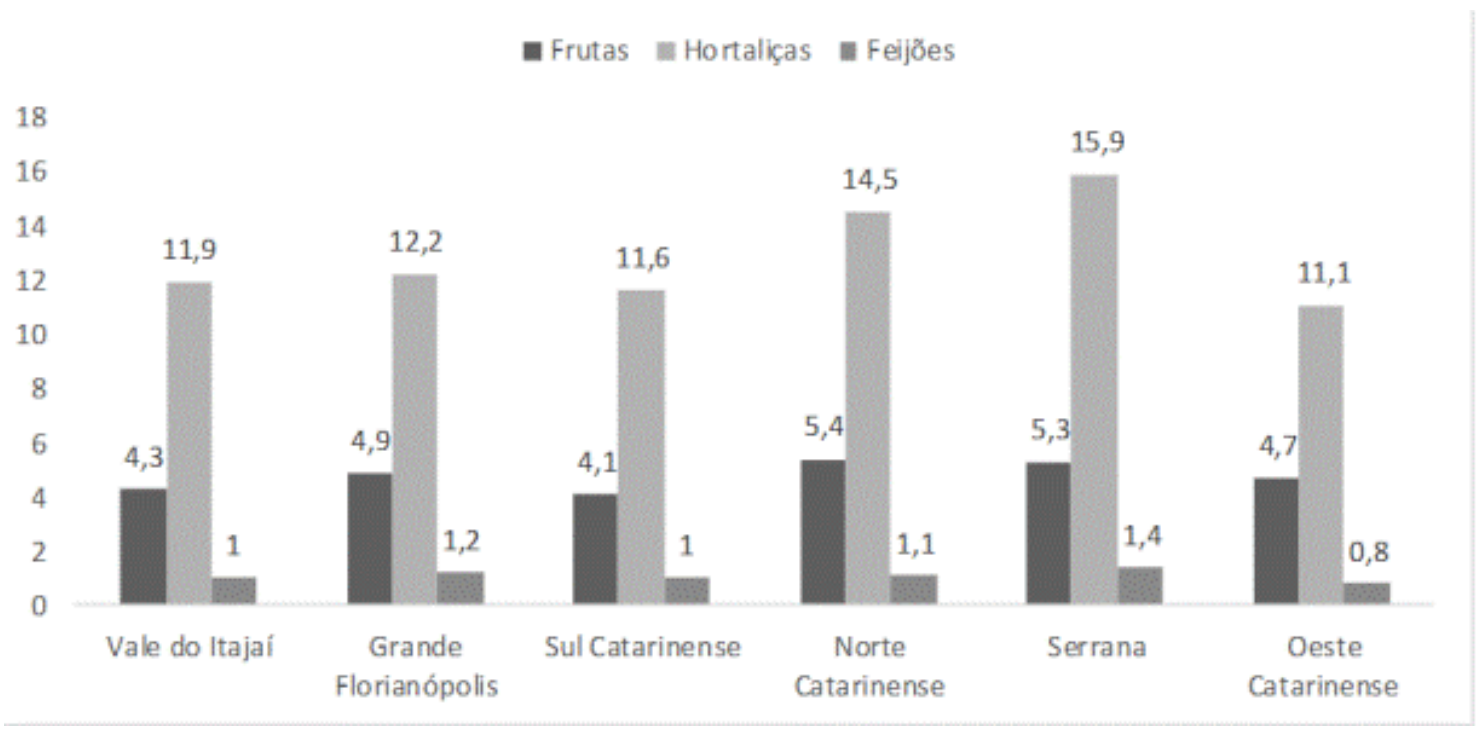

Fonte: Elaboração das autoras (2019).

De um modo geral, no conjunto das mesorregiões, observa-se pouca variedade nos grupos das frutas e dos feijões, quando comparados ao grupo das hortaliças. Em consequência, supõe-se que as Entidades Executoras podem estar solicitando esses alimentos em menor variedade devido a limitações de cultivo pelos agricultores 
Potencial contribuição da agricultura familiar para uma alimentação escolar saudável no estado de Santa Catarina no período de 2015 a 2017
Gisele Assumpção Vieira Carla Rosane Paz Arruda Teo Roberta Lamonatto Taglietti

familiares locais em determinadas regiões do estado. Essa ponderação reforça a importância de que seja fortalecido um processo de desenvolvimento da agricultura familiar, com foco no reconhecimento da dinâmica demanda-oferta-potencial. Nessa perspectiva, o PAA contribui para potencializar essa dinâmica, quando oportuniza que mercados institucionais, como o representado pelo PNAE, possam, por meio de sua demanda de alimentos, fortalecer a produção local e regional. Bezerra e Schneider (2012) corroboram essa informação ao entrevistarem agricultores paranaenses que relataram que o PAA possibilitou a diversificação de sua produção e inserção no mercado (BEZERRA; SCHNEIDER, 2012). Destaca-se, assim, que o acesso a mercados institucionais, promovido por políticas públicas intersetoriais que consideram a realidade como uma totalidade, surge como uma alternativa para dinamizar o setor da agricultura familiar, contribuindo, simultaneamente, para qualificar as condições de vida e saúde da população em geral (TEO et al., 2020).

Retomando a discussão, outra hipótese pertinente - e que não exclui a já mencionada - é a de que as Entidades Executoras podem não estar priorizando a variedade dos alimentos na elaboração das chamadas públicas, e sim o cumprimento do artigo 14 em termos de proporção da aplicação de recursos. Na promulgação da Lei n. 11.947/2009, que determina que pelo menos 30\% do recurso destinado pelo FNDE seja para a compra de alimentos oriundos da agricultura familiar, é necessário reconhecer que esse mecanismo deveria ser um incentivador para a diversificação produtiva e não apenas uma obrigação perante a legislação. Esse cenário, certamente, repercute na qualidade das refeições escolares e não favorece o desenvolvimento da agricultura familiar local em médio e longo prazo.

Entretanto, observa-se que, no estado de Santa Catarina, o cultivo de frutas vem ganhando espaço e contribui para a geração de renda de milhares de famílias de agricultores. Estima-se que cerca de 14 mil produtores cultivem mais de 55,0 mil hectares de frutas em lavouras permanentes, destacando-se o cultivo de maçã, banana, uva, pêssego/nectarina, maracujá e laranja, que representa em torno de $94 \%$ do valor bruto de produção. Em menor escala, ainda cabe mencionar a produção de outras variedades de frutas, como figo, kiwi, caqui, pera, tangerina, limão, amora, physalis, mirtilo e goiaba (GOULART JUNIOR; REITER; MONDARDO, 2016). Já em relação à produção de feijões, a agricultura familiar do estado se destaca na produção de feijão preto e feijão de cores, com predomínio do feijão carioca (EPAGRI/CEPA, 2018). 
Por outro lado, a demanda por parte da alimentação escolar pode estimular cultivos que antes eram pouco valorizados pelos produtores, como é o caso dos hortifrútis, conforme indicam Elias et al. (2019), em um estudo sobre os impactos socioeconômicos do PNAE na agricultura familiar em 31 municípios de Santa Catarina. Os autores apontam que tais demandas incentivam também a criação de agroindústrias familiares, viabilizando, desse modo, maior diversificação da produção. Esse fato também se deve à própria forma de organização dos agricultores, que avançou com o PNAE, especialmente por meio da inserção em cooperativas com vistas à participação no mercado das compras institucionais (ELIAS et al., 2019).

Estudo realizado por Ramos et al. (2017) com o objetivo de diagnosticar e analisar os fatores limitantes para a participação da agricultura familiar na alimentação escolar em Curuçá, no estado do Pará, identificou que o fato de o município possuir apenas uma associação de agricultores resultou na limitação da quantidade e da variedade de alimentos entregues para o PNAE. Nesse sentido, as autoras sugerem, para efetiva participação da agricultura familiar na alimentação escolar, a criação de cooperativas (RAMOS et al., 2017).

Evidentemente, é importante destacar também a participação de outros atores sociais nesse processo. As autoras Mossmann e Teo (2017), em estudo que visou conhecer as percepções de diferentes atores sociais sobre a Lei n. 11.947/2009 e sua implementação nas questões associadas à agricultura familiar, salientaram o papel que os nutricionistas responsáveis técnicos pelo PNAE - podem desempenhar ao inverter a lógica de execução do programa, tradicionalmente pautada na elaboração de cardápios e na consequente publicação de listas de compras sem conhecer a realidade agrícola da região e, portanto, sem considerar se as demandas do programa estão adequadas à produção da agricultura familiar local. Ao fazerem o processo inverso, partindo do reconhecimento da produção na direção da elaboração de cardápios (e das compras) que a contemplem, fica certamente favorecido o acesso dos agricultores familiares ao PNAE. Ademais, as autoras também reforçaram que "no nível local, a política se torna realidade a partir da leitura que fazem dela aqueles que a colocam em ação, em um movimento que não está isento de disputas e interesses dos mais diversos" (MOSSMANN; TEO, 2017, p. 41). Isso significa dizer que é fundamental que os diversos atores envolvidos com a implementação da política estejam mobilizados e comprometidos com sua materialização, em uma postura dialógica. 
Potencial contribuição da agricultura familiar para uma alimentação escolar saudável no estado de Santa Catarina no período de 2015 a 2017
Gisele Assumpção Vieira Carla Rosane Paz Arruda Teo Roberta Lamonatto Taglietti

Certamente, já se avançou muito no Brasil na construção de políticas relacionadas à SAN, na organização do PNAE e nas compras públicas, mas ainda é preciso fortalecer, especialmente, as compras da agricultura familiar pelo PNAE, pois permanecem muitas dificuldades neste processo, como as relativas a melhoria de infraestrutura, capacitação de colaboradores das escolas, assistência técnica e melhoria na capacidade dos agricultores, resolução de entraves na logística de entrega e capacitação de nutricionistas, para que desenvolvam cardápios nutricionalmente adequados e que representem a produção e a cultura alimentar locais. Apesar destes desafios, é motivo de orgulho dizer que o Brasil foi pioneiro nesta iniciativa e vem sendo modelo para outros países. Além disso, não há dúvidas dos efeitos positivos desta iniciativa para agricultores, comunidade, alunos e escolas (SCHWARTZMAN et al., 201b).

Retomando os achados do presente estudo, cabe apontar que foi constatada correlação entre a adequação à recomendação do FNDE (200g/semana de hortaliças e frutas) e as variedades de frutas $(r=0,480 ; p<0,01)$ e de hortaliças $(r=447 ; p<0,01)$ nas chamadas públicas (tabela 4). Sugere-se que isso seja uma evidência de que aquisições de uma maior variedade de frutas e hortaliças podem resultar em maior oferta desses alimentos na escola. Dito de outra forma, propõe-se que a variedade desses marcadores alimentares possa ser um indicador de qualidade da chamada pública com vistas a uma alimentação escolar saudável.

Também foi constatada correlação entre a variedade de frutas e a variedade de hortaliças $(r=0,620 ; p<0,01)$, ponderando-se que esse achado seja uma evidência da disposição da gestão pública para oferecer, na escola, boa variedade de alimentos reconhecidamente saudáveis e cujo consumo, no Brasil, é muito baixo. Além disso, essa observação pode evidenciar que a gestão pública reconhece e valoriza a vocação da agricultura familiar, assim como compreende a intencionalidade da Lei no sentido de que sua inserção na alimentação escolar deve se dar por meio dos alimentos in natura.

Nessa direção, argumenta-se que a relativamente baixa variedade de frutas constatada neste estudo pode ser resultante de outras dificuldades na dinâmica demandaoferta, que precisam ser mais bem exploradas em estudos futuros.

Do mesmo modo, foi observada correlação entre o per capita e a variedade de feijões $(r=535 ; \mathrm{p}<0,01)$, entre o per capita e a variedade de frutas $(\mathrm{r}=0,533 ; \mathrm{p}<0,01)$ e entre o per capita e a variedade de hortaliças $(\mathrm{r}=0,500 ; \mathrm{p}<0,01)$, reforçando a proposição 
Potencial contribuição da agricultura familiar para uma alimentação escolar saudável no estado de Santa Catarina no período de 2015 a 2017
Gisele Assumpção Vieira Carla Rosane Paz Arruda Teo Roberta Lamonatto Taglietti

de que quando esses alimentos são comprados em maior variedade as aquisições podem resultar em maior oferta na escola.

A esse propósito, o Guia alimentar da População Brasileira orienta que uma alimentação saudável deve pautar-se em uma variedade de alimentos que garanta uma alimentação nutricionalmente equilibrada. Para tanto, as escolhas alimentares devem ser baseadas em alimentos in natura ou minimamente processados, dando-se preferência aos alimentos de origem vegetal (feijões, frutas, hortaliças, raízes e tubérculos, cereais, castanha e nozes) e, em menores quantidades, em alimentos de origem animal (carnes, ovos, leite e queijos) (BRASIL, 2014).

Soares et al. (2017), em um estudo que objetivou conhecer o efeito dos critérios de compra do PNAE sobre a quantidade, variedade e origem dos alimentos adquiridos para a alimentação escolar, analisaram as listas de compras de alimentos de um município brasileiro para o período de dois anos antes e dois anos após a implementação da Lei n. 11.947/2009. Neste estudo, as autoras observaram que, com a inserção de alimentos da agricultura familiar, houve significativa redução de alimentos restritos (alto teor de sódio, açúcar, gorduras saturadas e trans) e aumento dos alimentos recomendados (frutas, hortaliças, cerais, alimentos integrais, entre outros) nas listas de compra do município (SOARES et al., 2017).

Em outra pesquisa, realizada por Amorim, Rosso e Bandoni (2016), que avaliou o perfil dos alimentos presentes nas 122 chamadas públicas de aquisição de alimentos para o PNAE em 99 municípios de São Paulo, foi identificado que os grupos das hortaliças e das frutas foram os mais presentes nos editais, representando, respectivamente, 50 e $31 \%$ dos alimentos listados nesses documentos (AMORIM; ROSSO; BANDONI, 2016).

Triches e Silvestri (2018), ao estabelecerem um comparativo entre a solicitação de alimentos nas chamadas públicas e a efetiva aquisição desses alimentos, no estado do Paraná, no ano de 2013, perceberam que o grupo mais solicitado foi o de laticínios $(59,77 \%)$, seguido pelo grupo das frutas, legumes e verduras $(26,36 \%)$, cereais e derivados $(8,23 \%)$, e panificados $(3,03 \%)$. Porém, em termos da efetivação das aquisições, analisadas por meio das prestações de contas dos municípios, a prevalência observada foi do grupo de frutas, legumes e verduras $(45,63 \%)$, seguido pelo de panificados (30,34\%), pelo de leite e derivados $(14,13 \%)$ e o de cereais e derivados $(7,46 \%)$. As autoras pontuam que esse fato pode ser decorrente de que frutas, legumes e 
Potencial contribuição da agricultura familiar para uma alimentação escolar saudável no estado de Santa Catarina no período de 2015 a 2017
Gisele Assumpção Vieira Carla Rosane Paz Arruda Teo Roberta Lamonatto Taglietti

verduras são produções características da agricultura familiar, sendo mais passíveis de oferta por estes produtores (TRICHES; SILVESTRI, 2018).

Em outro estudo, realizado em 14 municípios do estado de São Paulo, com o objetivo de avaliar a inserção de frutas e hortaliças provenientes da agricultura familiar no PNAE, Barone et al. (2016) apontam que 72,3\% dos nutricionistas entrevistados relataram que a inserção da agricultura familiar na alimentação escolar resultou em maior variedade e qualidade de frutas e hortaliças, aumentando o consumo destes alimentos entre os escolares.

Diante deste contexto, propõe-se que a análise das compras da agricultura familiar para a alimentação escolar evidencia que há uma tendência de aquisição de alimentos considerados mais saudáveis, em consonância com a Lei n. 11.947/2009, que determina a utilização de alimentos básicos na alimentação escolar, pautando-se na diversificação agrícola da região (BRASIL, 2009).

A esse respeito, Teo e Monteiro (2012) ponderam que, embora na Lei não esteja explicitado quais seriam os alimentos básicos, seria conveniente que essa lacuna fosse preenchida com uma nova concepção sobre alimentos básicos saudáveis, não deixando margem para flexibilizações na execução do programa que possam comprometer a qualidade da alimentação escolar. Além disso, os autores reiteram que a alimentação oferecida aos escolares seja baseada em alimentos in natura e minimamente processados (TEO; MONTEIRO, 2012).

Nessa perspectiva, a aquisição de alimentos da agricultura familiar pode contribuir para uma alimentação escolar mais saudável, favorecendo melhores condições nutricionais aos escolares. Para tanto, é necessário que as entidades executoras se empenhem na elaboração das chamadas públicas, de modo que a solicitação de alimentos considere a produção da agricultura familiar local com valorização de alimentos saudáveis.

Considera-se oportuno registrar, neste ponto, que este estudo apresenta limitações, visto que as chamadas públicas representam a intenção de compra de alimentos da agricultura familiar por parte das entidades executoras, não necessariamente expressando o que de fato se materializa como aquisição e, posteriormente, como oferta no ambiente escolar. Destaca-se, ainda, que vários fatores interferem na transposição dessa intencionalidade de compra para a realidade, como questões climáticas e de sazonalidade, 
Potencial contribuição da agricultura familiar para uma alimentação escolar saudável no estado de Santa Catarina no período de 2015 a 2017
Gisele Assumpção Vieira Carla Rosane Paz Arruda Teo Roberta Lamonatto Taglietti

capacidade produtiva e de atendimento da agricultura familiar, articulação intersetorial, entre outros.

No entanto, argumenta-se que os documentos analisados e os resultados obtidos possibilitaram elaborar uma caracterização da aquisição de marcadores alimentares saudáveis da agricultura familiar, sinalizando sua contribuição, em potencial, para a oferta de uma alimentação escolar adequada no estado de Santa Catarina, por meio de indicadores que demonstraram propriedade de evidenciar aspectos favoráveis e fragilidades nesse contexto. Ademais, pondera-se que os documentos analisados representam fontes adequadas de dados para os fins ora pretendidos, com baixo custo de coleta e de processamento.

Assim, propõe-se que a relevância deste estudo reside precisamente na possibilidade de que os aspectos favorecedores identificados sejam fortalecidos e as fragilidades, trabalhadas com foco na sua superação, com vistas a fazer avançar a contribuição da agricultura familiar para a alimentação escolar.

\section{Considerações finais}

No presente estudo, foi possível identificar a presença de marcadores alimentares saudáveis nos editais de chamada pública, sugerindo que a agricultura familiar pode contribuir para uma alimentação escolar mais saudável no estado de Santa Catarina. A esse propósito, destaca-se a quantidade de frutas e hortaliças que contempla a recomendação do FNDE no que se refere à oferta semanal destes alimentos. No entanto, pondera-se que a recomendação mínima para oferta de frutas e hortaliças no PNAE deveria ser mais expressiva, aproximando-se das diretrizes mundiais para uma alimentação adequada e saudável. Além disso, propõe-se que a oferta de frutas e hortaliças indicada pelo FNDE deveria ser proporcional ao tempo de permanência do estudante no ambiente escolar, entendendo a participação que as refeições escolares podem assumir, em termos nutricionais, para o grupo usuário do programa.

Em relação ao grupo dos feijões, embora tenha sido solicitado nas chamadas públicas, a quantidade foi ínfima, e apesar de existirem outros processos para aquisição deste grupo alimentar, este pode ser um indicador, a exemplo do que ocorre na população brasileira, de um distanciamento destes alimentos básicos do consumo habitual nas refeições diárias, o que requer, por meio de ações de educação alimentar e nutricional, 
Potencial contribuição da agricultura familiar para uma alimentação escolar saudável no estado de Santa Catarina no período de 2015 a 2017
Gisele Assumpção Vieira Carla Rosane Paz Arruda Teo Roberta Lamonatto Taglietti

um resgate de hábitos alimentares tradicionais, que nutricionalmente são caracterizados pela oferta de alimentos in natura e minimamente processados, como os feijões. Desse modo, sugere-se que mais estudos sejam realizados a fim de identificar a presença de feijões nas refeições escolares.

Quanto à variedade dos marcadores alimentares saudáveis, percebe-se que a presença de frutas e feijões nas chamadas públicas dos municípios teve, em média, menor variedade em comparação às hortaliças, indicando que são necessários mais estudos para buscar entender se há pouca variedade na produção dos agricultores familiares participantes do PNAE e as Entidades Executoras reconhecem essas limitações ou se estão solicitando em menor variedade, sem reconhecer a vocação agrícola da região e, consequentemente, não considerando que uma alimentação saudável precisa também ser variada.

Por fim, é importante destacar a necessidade de o profissional nutricionista conhecer a vocação agrícola da região em que está inserido e contribuir com o fortalecimento e o desenvolvimento desta região, mediante articulações intersetoriais que viabilizem a elaboração de editais de chamada pública que priorizem a produção local e, por conseguinte, de cardápios coerentes com esta produção.

Os resultados desta pesquisa apontam a necessidade de estudos que avancem na análise da qualidade dos produtos adquiridos da agricultura familiar e de sua potencial contribuição nutricional para o público atendido pelo PNAE. Nessa direção, em uma abordagem interdisciplinar, se perspectiva uma importante contribuição, também, para o desenvolvimento da agricultura familiar e, portanto, para o desenvolvimento local.

\section{REFERÊNCIAS}

AMORIN, Ana Laura Benevenuto; ROSSO, Veridiana Vera; BANDONI, Daniel Henrique. Acquisition of family farm foods for school meals: Analysis of public procurements within rural family farming published by the cities of São Paulo state. Revista de Nutrição, Campinas, v. 29 n. 2 p. 297-306, mar./abr., 2016.

BARONE, Bruna et al. Oferta de frutas e hortaliças da agricultura familiar na alimentação escolar. Vigilância Sanitária em Debate, Rio de Janeiro, v.4, n.3, p. 8695, ago. 2016.

BATISTA FILHO, Malaquias; RISSIN, Anete. A transição nutricional no Brasil: tendências regionais e temporais. Caderno de Saúde Pública, Rio de Janeiro, v. 19, n. 1, p. 181-191, jan. 2003. 
Potencial contribuição da agricultura familiar para uma alimentação escolar saudável no estado de Santa Catarina no período de 2015 a 2017
Gisele Assumpção Vieira

Carla Rosane Paz Arruda Teo

Roberta Lamonatto Taglietti

BEZERRA, José Arimatea Barros. Alimentação e escola: significados e implicações curriculares da merenda escolar. Revista Brasileira de Educação, Rio de Janeiro, v. 14, n. 40, p. 103-115, jan./abr. 2009.

BEZERRA, Islandia; SCHNEIDER. Produção e consumo de alimentos: o papel das políticas públicas e consumo entre o plantar e o comer. Revista Unioeste, v. 15, n.20. p. 35-61, jan/jun 2012.

BRASIL. Lei n. 11.947 de 16 junho de 2009. Dispõe sobre o atendimento da alimentação escolar e do Programa Dinheiro Direto na Escola aos alunos da educação básica. Diário Oficial da União, Brasília, DF, 17 jun. 2009.

BRASIL. Ministério da Saúde. Secretaria de Atenção à Saúde. Departamento de Atenção Básica. Guia Alimentar para a População Brasileira. 2 ed. Brasília: Ministério da Saúde, 2014. ISBN 978-85-334-2176-9.

BRASIL. Ministério da Saúde. Secretaria de Atenção à Saúde. Departamento de Atenção Básica. Guia Alimentar para a População Brasileira: promovendo a alimentação saudável. Brasília: Ministério da Saúde, 2008. ISBN 85-334-1154-5.

BRASIL. Ministério da Saúde. Secretaria de Atenção à Saúde. Departamento de Atenção Básica. Orientações para avaliação de marcadores de consumo alimentar na atenção básica. Brasília: Ministério da Saúde, 2015. ISBN 978-85-334-2248-3.

BRASIL. Fundo Nacional de Desenvolvimento da Educação. Coordenação-Geral do Programa Nacional de Alimentação Escolar. Aquisição de produtos da agricultura familiar para a alimentação escolar. 2. ed. Versão atualizada com a Resolução CD/FNDE n. 04/2015. 2016.

BRASIL. Fundo Nacional de Desenvolvimento da Educação. Resolução CD/FNDE n. 26, de 17 de junho de 2013. Dispõe sobre o atendimento da alimentação escolar aos alunos da educação básica no âmbito do Programa Nacional de Alimentação Escolar PNAE. Diário Oficial da União, Brasília, DF, 18 jun. 2013.

CENTRAIS DE ABASTECIMENTO DO ESTADO DE SANTA CATARINACEASA-SC. Cotação de preços. 2018. Disponível em: http://www.ceasa.sc.gov.br/index.php/cotacao-de-precos. Acesso em: 15 de ago. 2018.

COSTA, Larissa da Cunha Feio; VASCONCELOS, Francisco de Assis Guedes, CORSO, Arlete Catarina Tittoni. Fatores associados ao consumo adequado de frutas e hortaliças em escolares de Santa Catarina, Brasil. Caderno de Saúde Pública, Rio de Janeiro, v. 28, n.6, p. 1133-1142, jun. 2012.

ELIAS, Lilian de Pellegrini et al.. Impactos Socioeconômicos do Programa Nacional de Alimentação Escolar na Agricultura Familiar de Santa Catarina. Revista de Economia e Sociologia Rural, Brasília, v. 57, n.2, p. 215-233, jul. 2019.

EPAGRI/CEPA. Síntese anual da Agricultura de Santa Catarina 2017-2018. Florianópolis: EPAGRI, 2018. 206 p. 
FREITAS, Maria do Carmo Soares, et al. Escola: lugar de estudar e de comer. Ciência \& Saúde Coletiva, Rio de Janeiro, v.18, n.4, p. 979-985, abr. 2013.

FURH, Aline Luiza; TRICHES, Marcia Rozane. Qualidade da alimentação escolar a partir da aquisição de produtos da agricultura familiar. Segurança Alimentar e Nuticional, Campinas, v. 24, n. 2, p. 113-124, jul./dez. 2017.

GOULART JUNIOR, Rogério; REITER, Janice Maria Waintuch; MONDARDO, Marcia. Panorama da fruticultura Catarinense: Levantamento de dados a safra 2014-15. In: V Encontro de Economia Catarinense, 2016, Blumenau. Anais [...]. Blumenau: FURB, 2016.

IBGE. Instituto Brasileiro de Geografia e Estatística. Censo Agropecuário 2017. In: IBGE. Sidra: sistema IBGE. Disponível em: https://censos.ibge.gov.br/agro/2017/. Acesso em: 11 ago. 2020.

IBGE. Instituto Brasileiro de Geografia e Estatística. IBGE Cidades. Disponível em: https://cidades.ibge.gov.br/. Acesso em: 07 jun. 2019.

IBGE. Instituto Brasileiro de Geografia e Estatística. Pesquisa Nacional de Saúde Escolar. Rio de Janeiro: Instituto Brasileiro de Geografia e Estatística. Rio de Janeiro, 2016.

IBGE - Instituto Brasileiro de Geografia e Estatística. Pesquisa de Orçamentos Familiares 2008-2009 - POF. Rio de Janeiro, 2010.

INEP. Instituto Nacional de Estudos e Pesquisas Educacionais Anísio Teixeira -INEP. Censo escolar de 2015. Disponível em: http://portal.inep.gov.br Acesso em: 07 de ago. 2018.

INEP. Instituto Nacional de Estudos e Pesquisas Educacionais Anísio Teixeira -INEP. Censo escolar de 2016. Disponível em: http://portal.inep.gov.br. Acesso em: 07 de ago. 2018.

INEP. Instituto Nacional de Estudos e Pesquisas Educacionais Anísio Teixeira -INEP. Censo escolar de 2017. Disponível em: http://portal.inep.gov.br. Acesso em: 07 de ago. 2018.

MARCONDES, Tabajara. A agropecuária em Santa Catarina: cenário atual e principais tendências. Revista NECAT, Florianópolis, v, 5, n. 9, p. 8-38, jan/jun. 2016.

MARTINELLI, Suellen Sechi et al. Composição dos cardápios escolares da rede pública de ensino de três municípios da região sul do Brasil: uma discussão perante a legislação. Demetra: alimentação, nutrição \& Saúde, Rio de Janeiro, v. 9, n. 2, p. 515535, mai. 2014.

MENDONÇA, Cristina Pinheiro; ANJOS, Luiz Antônio. Aspectos das práticas alimentares e da atividade física como determinantes do crescimento do sobrepeso/obesidade no Brasil. Cadernos de Saúde Pública, Rio de Janeiro, v. 20, n.3, p. 698-709, mai./jun. 2004. 
Potencial contribuição da agricultura familiar para uma alimentação escolar saudável no estado de Santa Catarina no período de 2015 a 2017
Gisele Assumpção Vieira

Carla Rosane Paz Arruda Teo

Roberta Lamonatto Taglietti

MIOR, Luiz Carlos et al. Redes, agroindústrias familiares e os novos mercados em Santa Catarina. In: Estevam, Dimas de Oliveira; Mior, Luiz carlos. Inovações na agricultura familiar: as cooperativas descentralizadas em Santa Catarina. Florianopolis: Insular, 2014. p. 73-100.

MONTEIRO, Carlos Augusto, et al. The UN Decade of Nutrition, the NOVA food classification and the trouble with ultra-processing. Public Health Nutrition.

Cambridge, v.21, n.1, p. 5-17, jan. 2017.

MOSSMANN, Márcia Pozzagnol; TEO, Carla Rosane Paz Arruda. Alimentos da agricultura familiar na alimentação escolar: percepções dos atores sociais sobre a legislação e sua implementação. Interações, Campo Grande, v. 18, n. 2, p. 31-43, abr./jun. 2017.

NOLL, Priscilla Rayanne e Silva et al. Ultra-processed food consumption by Brazilian adolescents in cafeterias and school meals. Nature. Londres, v. 9, n. 7162, p. 1-8, mai. 2019.

RAMOS, Maiara dos Santos et al. Produtos da agricultura familiar na alimentação escolar do município de Curuçá-PA: desafios e perspectivas. Agroecossistemas, v. 9, n. 1, p. 131-146, jan, 2017.

ROCKETT, Fernanda Camboim et al. Family farming and school meals in Rio Grande do Sul, Brazil Ciência Rural, Santa Maria, v.49, n.2, p. 1-12, mar. 2019.

SCHWARTZMAN, Flávia et al. Antecedentes e elementos da vinculação do programa de alimentação escolar do Brasil com a agricultura familiar. Cadernos de Saúde Pública, Rio de Janeiro, v. 33, n. 12, p.1-15, dez. 2017a.

SCHWARTZMAN, Flávia et al. É preciso seguir com as compras diretas da agricultura familiar local pelo Programa Nacional de Alimentação Escolar. Cadernos de Saúde Pública, Rio de Janeiro, v. 33, n.12, p.1-2, dez. 2017 b.

SILVA, Edleuza Oliveira; SANTOS, Ligia Amparo; SOARES, Micheli Dantas. Alimentação escolar e constituição de identidades dos escolares: da merenda para pobres ao direito à alimentação. Caderno de Saúde Pública, Rio de Janeiro, v. 34, n. 4, 1-13, mar. 2018.

SOARES, Panmela et al. The effect of new purchase criteria on food procurement for the

Brazilian school feeding program. Appetite, Amsterdam, p. 288-294, out. 2017.

STURION, Gilma Lucazechi, et al. Fatores condicionantes da adesão dos alunos ao Programa de Alimentação Escolar no Brasil. Revista de Nutrição, Campinas, v.18, n.2 p. 167-181, mar./abr, 2005.

TEO, Carla Rosane Paz Arruda et al. Articulação entre agricultura familiar e alimentação escolar em municípios de pequeno porte. Campo-território: revista de geografia agrária, Uberlândia, v. 11, n. 24, p. 175-199, ago. 2016. 
Potencial contribuição da agricultura familiar para uma alimentação escolar saudável no estado de Santa Catarina no período de 2015 a 2017
Gisele Assumpção Vieira

Carla Rosane Paz Arruda Teo

Roberta Lamonatto Taglietti

TEO, Carla Rosane Paz Arruda; MONTEIRO, Carlos Augusto. Marco legal do Programa Nacional de Alimentação Escolar: uma releitura para alinhar propósitos e prática na aquisição de alimentos. Revista de Nutrição, Campinas, v. 25, n. 5, p. 657668, out. 2012.

TEO, Carla Rosane Paz Arruda. BACCARIN, José Giacomo; TRICHES, Rozane Marcia; LUTINSKI, Junir Antonio; TAGLIETTI, Roberta Lamonatto. Aquisição de alimentos da agricultura familiar para a alimentação escolar em Santa Catarina, 20122014. Revista Grifos, v. 28, n. 47, p. 73-93, Jul./Dez. 2019.

TEO, Carla Rosane Paz Arruda et al. Agricultura familiar, alimentação escolar e a geração de oportunidades sociais para o desenvolvimento: experiências catarinenses. Grifos, Chapecó, v.29, n.49, p. 67-88, abr./ago. 2020.

TOYOYOSHI, Juliana Yumi et al. Avaliação da aquisição de gêneros alimentícios provenientes da agricultura familiar para a alimentação escolar. O Mundo da Saúde, São Paulo, v.37, n.3, p. 329-335, ago. 2013.

TRICHES, Rozane Marcia; SILVESTRI, Fernanda. Adequação das chamadas públicas para aquisição de produtos da agricultura familiar para a alimentação escolar.

Desenvolvimento em Questão, Ijuí, v. 16, n. 44, p.233-259, jul./set. 2018.

WHO/FAO. World Health Organization. Food and Agricultural Organization. Diet, Nutrition and the Prevention of Chronic Diseases. Report of a Joint WHO/FAO Expert Consultation, Geneva, 28 January - 1 February 2002. Geneva, 2002. (WHO Technical Report Series, 916). Disponível em: http://apps.who.int/iris/bitstream/handle/10665/42665/WHO_TRS_916.pdf. Acesso em 09 ago. 2018.

Recebido em 04/03/2020.

Aceito para publicação em 21/05/2020. 